\title{
The influence of Thyristor controlled series capacitor on distance protection relay and its mitigation
}

\author{
Atulkumar Shuklaji Nikhade ${ }^{1}$, Vivek Yadav ${ }^{2}$, Rahul P. Dhote ${ }^{3}$,Snusha R. Dharmik ${ }^{4}$ \\ Student, Electrical Engineering Department, R.K.D.F. Institute of science, Bhopal (M.P.), India ${ }^{1}$ \\ Assistant Professor, Electrical Engineering Department, R.K.D.F. Institute of science, Bhopal (M.P.), India ${ }^{2}$ \\ Assistant Professor, Electrical Engineering Department, V.I.T. College of Engineering, Nagpur (M.H.), India ${ }^{3}$ \\ Lecturer, Electrical Engineering Department, Priyadarshini Polytechnic, Nagpur (M.H.), India ${ }^{4}$
}

\begin{abstract}
In modern power transmission systems suffering from large voltage drop and transfer capability of power reduces due to the line reactance and thermal limits. Therefore, Thyristor Controlled Series Capacitor (TCSC) has been used to improve the power transfer capability of transmission line by changing the reactive power distribution in the power system. This paper discusses the effect of TCSC for power enhancement capability. Further, the effect of TCSC on distance protection relay of transmission lines due to the fast response time of thyristor controllers with respective that of the protective devices is also investigated.
\end{abstract}

Keywords: Transmission line protection, distance relay, FACTS Devices, active power, reactive power, TCSC

\section{INTRODUCTION}

The rapidly growth in electrical power system has that of the protective devices. Also the study on a scheme gradually increased to the development of control devices. to mitigate the effect of the Thyristor Controlled Series These control devices are used in series and shunt, active Capacitor (TCSC) on distance protection. and passive, controlled and switched categories in power system. Overall finally these devices are used to increase transmittable power, improve power system stability and enhance system voltage. Thyristor Controlled Series Capacitor (TCSC) is considered the first generation of FACTS devices. Using the TCSC and its protection elements metal oxde varistor (MOV) as advanced series compensation in the midpoint of transmission line create certain problems for the line protective devices especially the distance relay. These problems overcome in case of fixed compensation. TCSC is one of the Flexible AC Transmission Systems (FACTS) devices which is used for all mentioned purposed. However, FACTS device has a profound impact on the operation of other equipment in the system, such as transmission lines protection.

Distance protection relays have been mostly used as the primary protection in high voltage transmission lines due to their simple operating principle and capability to work independently. However, the implementation of FACTS Controllers in power system transmission for improving the power system controllability and stability have introduced new power system issues in the field of power system protection that must be Considered and analyzed. The presence of the FACTS devices in the faulted loop introduces changes to the line parameters seen by the distance relay. The effect of FACTS device would affect both the steady state and transient Characteristics of the apparent impedance seen by distance relays due to the fast response time of FACTS Controllers with respect to

\section{TCSC MODELLING AND STEADY STATE MODES OF OPERATION}

\section{A. TCSC Model}

Fig. (1) shows a TCSC module consist of Basically, a series capacitor (C), in parallel with a Thyristor Controlled Reactor (TCR) (Ls). A metal oxide varistor (MOV), essentially a nonlinear resistor, is connected across the series capacitor to prevent the occurrence of high capacitor over voltages. The amount of series compensation in the capacitive operating region is increased (or decreased) by varying the thyristor firing angle $\alpha$. The total impedance of TCSC is given in equation (1).

Where,

$$
X_{T C S C}=\frac{X_{C} X_{L}}{X_{C}-X_{L}(\alpha)}
$$

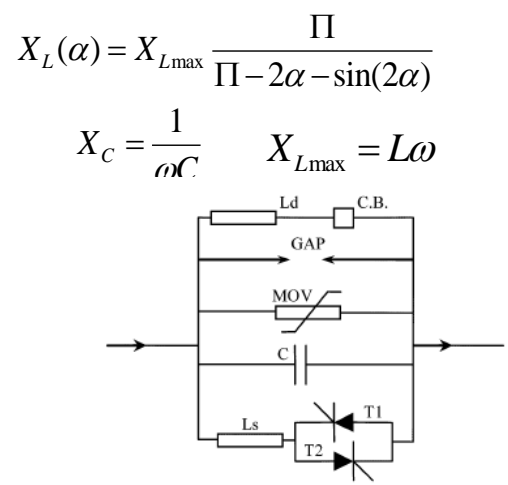

Fig.1. Practical TCSC module 


\section{B. TCSC Modes of Operation in Steady State \\ Different operanting modes of a TCSC are as follows.}

Blocking mode: In blocking mode, it is also called as the waiting mode, the firing pulses to then thyristor valves are blocked. When the thyristors are operating and a blocking command is given, then the thyristors turn off as soon as the current through them reaches a zero crossing.

Bypass mode: In the bypasss mode, thyristor valve is triggered continuously. Thyristor valve stays conducting all the time and the TCSC behaves like a parallel connection of the series capacitor bank with the inductor in the thyristor valve. However, the net current through the module is inductive, the susceptance of the reactor is chosen to be higher that of the capacitor.

Capacitive boost mode: When the trigger pulse is applied to the thyristor having forward voltage just before the capacitor voltage crosses the zero line a capacitor discharge current pulse will passed through the parallel inductive branch. The discharge current pulse adds to the line current through the capacitor bank.

Inductive boost mode: In the inductive boost mode circulating current in the thyristor branch is larger than the line current. In this mode, large thyristor currents result and further the capacitor voltage waveform is very much distorted from its sinusoidal shape. The peak voltage appears close to the turn on. The poor waveform and the high valve stress make in this mode less attractive for steady state operation.

\section{TCSC Control methods}

Types of control methods used in TCSC are as follows.

Open-loop Control method: In this method, it is simplest for TCSC, in which firing delay angle $\alpha$ is obtained directly from the reactance order $\mathrm{X}_{\mathrm{ref}}$.

Close-loop Control method: It is common control method in automation control area. There are three methods are used in closed loop control methods,

i) Constant Impedance Control Method (CI)

ii) Constant Current Control Method (CC)

iii) Constant Power Control Method (CP)

In this paper, the constant impedance control method is used to produce the pulse for thyristor valve of TCSC. The outline of this control scheme is shown in Fig. (2). the measured impedance is comparing with the actual reference value and the error is modulated by PI controller to the firing delay angle error.

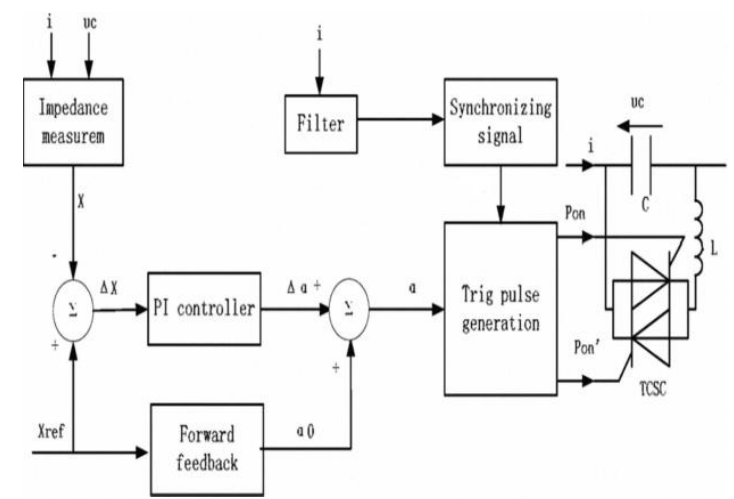

Fig. 2. TCSC closed - loop constant reactance control methodology

\section{B Y USING MHO DISTANCE PROTECTION RELAY MEASURED IMPEDANCE}

In distance protection division of the voltage at the relaying point by the measured current. The apparent impedance so calculated is compared with the reach point impedance. When the measured impedance $\left(Z_{\text {seen }}\right)$ is less than the reach point impedance, and then assumed that a fault exists on the line between the relay and the reach point. The reach point of a relay is the point along the line impedance locus that is intersected by the boundary characteristic of the relay. It is used for protection of EHV and HV transmission lines. The basic principle of operation of distance protection relay is shown in figure. 3 .

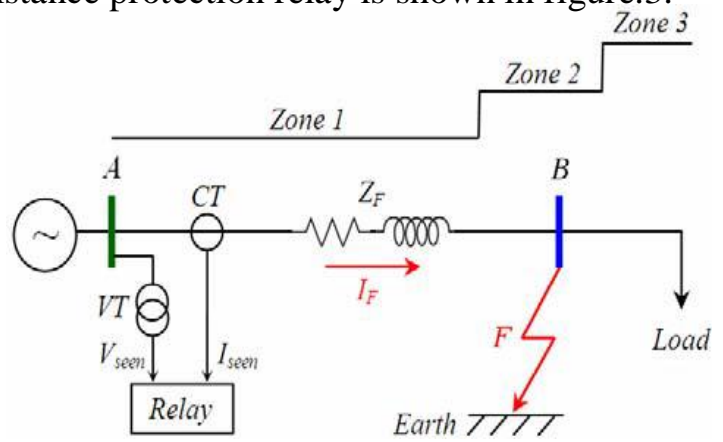

Fig.3. MHO distance protection in case of phase to earth fault.

The input is fed to the MHO distance relay point the phase voltages and line currents transformed with the supporting voltage transformer (VT) and current transformers (CT). The voltage would fall towards zero at the point of the fault. In case of earth fault, The impedance measured Zseen in phase (A) is calculated by flowing equation (2)

$$
\begin{gathered}
Z_{\text {seen }}=\frac{V_{\text {relay }}}{I_{\text {relay }}}=\frac{V_{A}}{I_{A}+K_{0} I_{T}} \\
K_{0}=\frac{Z_{0}-Z_{1}}{3 Z_{1}} \\
I_{T}=I_{A}+I_{B}+I_{C}
\end{gathered}
$$


INTERNATIONAL JOURNAL OF INNOVATIVE RESEARCH IN ELECTRICAL, ELECTRONICS, INSTRUMENTATION AND CONTROL ENGINEERING Vol. 2, Issue 12, December 2014

\section{A.Transmission line with TCSC in midline.}

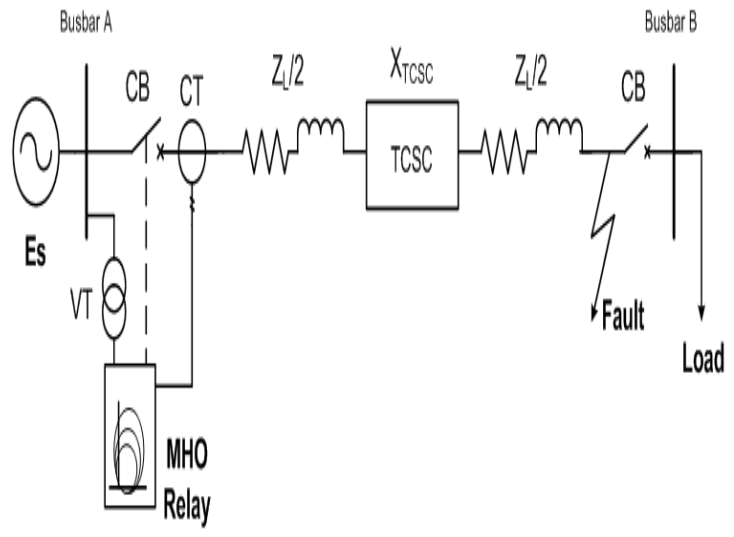

Fig.4. Phase to earth fault current calculation on presence of a TCSC

With TCSC inserted in midline of transmission line the total impedance of transmission line $\left(Z_{A B-T C S C}\right)$ is given by,

$$
Z_{A B-T C S C}=R_{A B}-j\left[X_{A B}-X_{T C S C}(\alpha)\right]_{(3)}
$$

\section{EFFECT OF TCSC ON DISTANCE PROTECTION}

As equation (3) shows that when the TCSC is connected in the middle of transmission line with the distance relay. It changes the line impedance and the relay may over reaches or under reaches depending upon the delay angle.

$\boldsymbol{C A S E - 1 : ~ T C S C}$ will be active in capacitive mode, it will add the negative reactance $(-X c)$ with the actual line reactance $\left(\mathrm{X}_{\mathrm{L}}\right)$. In this position the relay will over reach as the measured impedance will be less than the actual impedance of the line the relay can sense the fault beyond its operating reach.

CASE-2: TCSC will be active in capacitive mode, this mode will add the high value of positive reactance. In this position the relay will under reach as the measured impedance will be more than the below its operating reach. The relay cannot sense even a fault occurs in its reach hence under reach.

\section{SIMULATION RESULT}

\section{A. Simulation results (fault at $65 \mathrm{~km}$ ):}
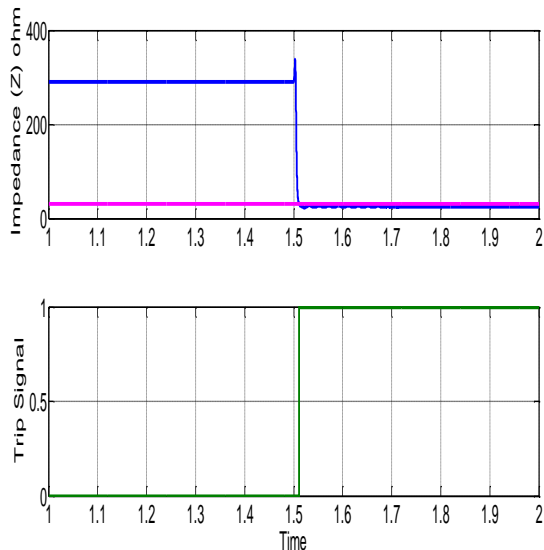

Fig. 5. Simulation results without TCSC (fault at $65 \mathrm{~km}$ ).
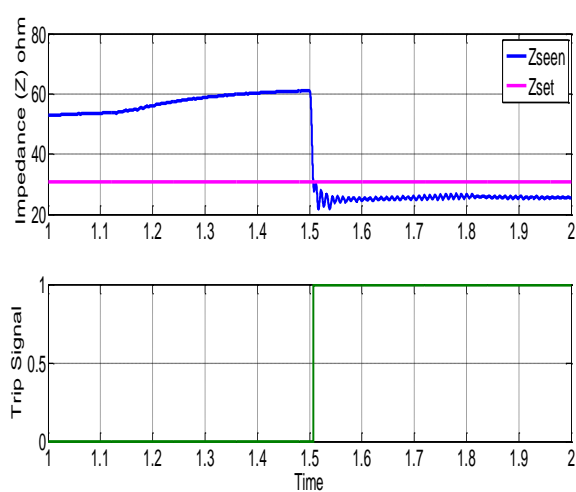

Fig. 6. Simulation results with TCSC (fault at $65 \mathrm{~km}$ ) B. Simulation results (fault beyond reach):
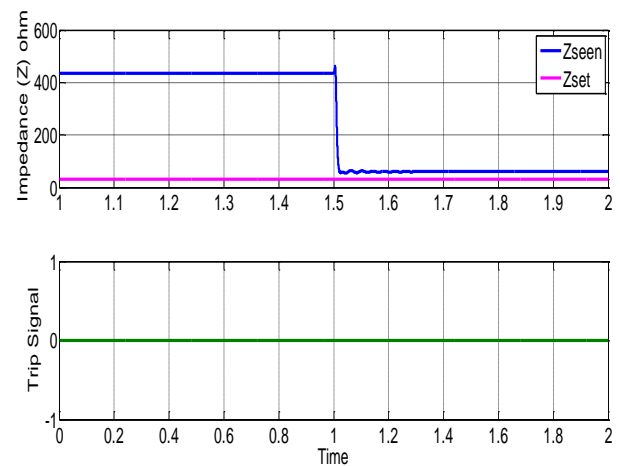

Fig. 7. Simulation results without TCSC (fault beyond reach).
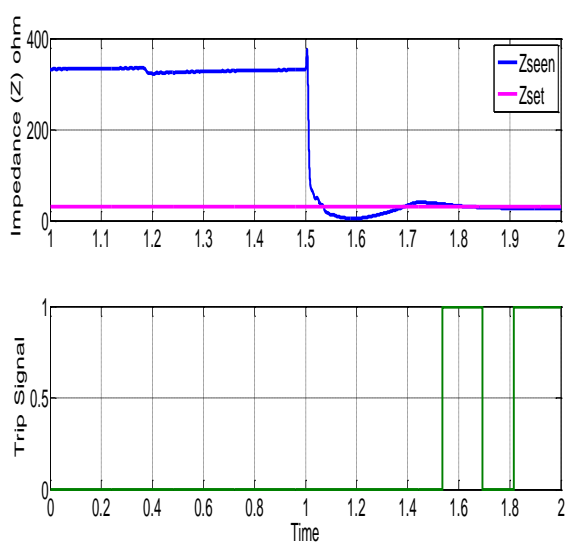

Fig. 8. Simulation results with TCSC (fault beyond reach).

C. Simulation results proposed mitigation scheme TCSC (fault beyond reach):
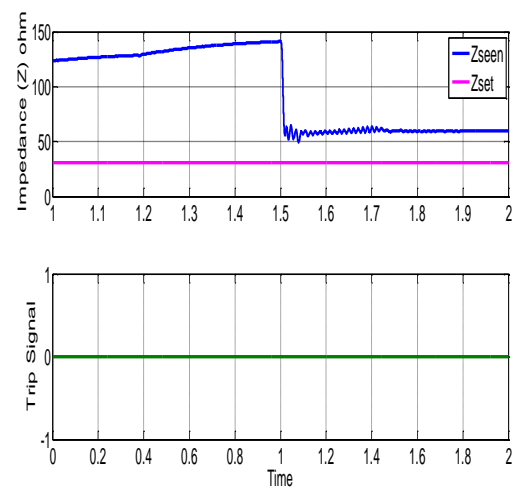

Fig. 9. Simulation results with new proposed mitigation scheme TCSC (Fault beyond reach) 


\section{CONCLUSION}

In this project, the effect of TCSC on the protective zone is studied. The simulation results show clearly the impact of TCSC on MHO distance relay performance. The impedance $Z_{\text {seen }}$ is influenced by the injected voltage $\mathrm{V}_{\text {TCSC }}$ of the TCSC. Since deviation of the measured impedance is not constant, because of the varying parameters of the injected reactance by TCSC. The proposed work presents mitigation technique with the modification of signals input to the mho relay i.e. modification of relay. In addition used of FCL is also proposed as one of the mitigation technique. In order to increase the total system protection performance and avoid unwanted tripping of circuit breaker in the presence of series FACTS devices compensator on electrical transmission lines care must be taken. For specified system, setting for different protection zones can be achieved based on the proposed setting principles.

\section{REFERENCES}

[1] N. G. Hingorani and L. Gyugyi, Understanding FACTS: Concepts $\&$ Technology of Flexible AC Transmission Systems. New York: Wiley, Nov. 1999.

[2] Y. Xiao, Y. H. Song, C. C. Liu, and Y. Z. Sun, "Available Transfer Capability Enhancement using FACTS devices," IEEE Trans. Power Syst., vol. 18, no. 1, pp. 305-312, Feb. 2003.

[3] A. D. D. Rosso, C. A. Canizares and V. M. Dona, "A study of TCSC controller design for power system stability improvement", IEEE Trans. Power Syst., vol. 18, no. 4, (2003) November, pp. 1487-1496.

[4] L. Felipe Willcox de Souza, E. Hirokazu Watanabe and J. Eduardo da Rocha Alves, Jr., "Thyristor and Gate-Controlled Series Capacitors: A Comparison of Components Rating", IEEE Transactions On Power Delivery, vol. 23, no. 2, (2008) April.

[5] A. Pillay, SAIE and B. S. Rigby, "Investigations into the effect of inductor size on the performance of $\mathrm{f}$ Thyristor Controlled Series Capacitor", AFRICON, 7th AFRICON Conference in Africa, (2004) September 1517.

[6] K. Satyanarayana, B. K. V. Prasad and K. Saikrishna, "Effect of Series FACTS Devices on Distance Protection", International Conference on Sustainable Energy and Intelligent Systems, pp. 36 41, July 2011.

[7] R. J. Marttila, "Performance of distance relay MHO elements on MOV, protected series-compensated transmission lines," IEEE Trans. Power Del., vol. 7,no. 3, pp. 1167-1178, Jul. 1992.

[8] Premalata Jena and Ashok Kumar Pradhan, "Directional Relaying in the Presence of a thyarister Controlled Series Capacitor", IEEE Transactions on Power Delivery,Vol.28, No.2, April 2013.

[9] Kazemi, S. Jamali, H. Shateri, "Distance Relay Over-Reaching due to TCSC Presence on Second Circuit of Double Circuit Line", POWERENG 2007, April 12-14, 2007, Setubal, Portugal.

[10] M. Khederzadeh and T. S. Sidhu, "Impact of TCSC on the protection of transmission lines," IEEE Trans. Power Del., vol. 21, no. 1, pp. 80-87, Jan. 2006.

[11] S.A.A. Shahriari , M. HosseiniAbardeh , A. YazdianVarjani and M. Mohamadian," Using Fault Current Limiter to Minimize Effect of Thyristor Controlled Series Capacitor on Over Reach Problem of Distance Protection",Power system conference and exposition 2009 IEEE/PES.

[12] A. A. Girgis, A. A. Sallam, and A. Karim El-din, "An adaptive protection scheme for advanced series compensated (ASC) transmission line," IEEE Trans. Power Del., vol. 13, no. 2, pp. 414-420, Apr. 1998. 